\title{
A IMPORTÂNCIA DO COMPLIANCE PARA A EFETIVAÇÁO DA GOVERNANÇA PÚBLICA NA ADMINISTRAÇÃO MUNICIPAL
}

\author{
THE IMPORTANCE OF COMPLIANCE FOR \\ THE ACCOMPLISH OF PUBLIC GOVERNANCE \\ IN MUNICIPAL ADMINISTRATION
}

PABlo Esteban FABRICIO CABALlERO ${ }^{1}$

ALFREDO COPETTI NETO ${ }^{2}$

\section{RESUMO}

Este artigo tem por finalidade evidenciar a importância dos programas de compliance na administração, em especial nos municípios, para a efetivação da governança pública. Para isso, utiliza-se o método de abordagem dedutiva através de técnica essencialmente crítica, de forma que serão analisados os conceitos que envolvem a matéria, o surgimento e expansão do compliance no Brasil e sua relação com a governança pública. Da mesma forma, são feitas considerações acerca da adoção desse mecanismo pela administração, a partir de leis, orientações e exemplos surgidos da competência da União e dos Estados. A partir disso, a ideia é demonstrar as ferramentas dos programas de compliance no setor público e sua aplicação fundamental para maior efetivação e aprimoramento da governança pública municipal. Ao final, conclui ser fundamental e positiva a aplicação dos programas de compliance como ferramenta de efetivação da governança pública nos municípios, especialmente por ter como consequência a redução de riscos à administração e pelo fato de se apresentar como mecanismo essencial para o fortalecimento ético e eficiente no setor público.

Palavras-chave: Administração Pública Municipal. Compliance. Governança. Integridade.

1 Bacharel em Direito pela Universidade Estadual do Oeste do Paraná. Pós-graduando em Compliance e Integridade Corporativa pela PUC-MG. Secretário da Comissão de Compliance Jurídico da OAB - Foz do Iguaçu. ORCID iD: https://orcid. org/0000-0002-4657-8903. E-mail: pablofabricio09@gmail.com.

2 Doutor em Teoria do Direito e da Democracia pela Università degli Studi Roma Tre (UNIROMATRE), Possui pós-doutorado na Universidade do Vale do Rio dos Sinos (UNISINOS) e Mestrado em Direito Público (Filosofia do Direito) pela Universidade do Vale do Rio dos Sinos (UNISINOS). Professor Visitante na Universitá di Roma (La Sapienza), Professor Adjunto de Teoria do Direito da Universidade Estadual do Paraná (UNIOESTE), Professor do PPG-G UniFG e da Univel. Consultor Ad Hoc CAPES. É membro fundador do "Centro di Studi di Diritto dellEconomia Brasile-Italia". Membro da Rede Brasil-Itália-Espanha de Direito Público. Membro do Comitê Brasileiro de Compliance. ORCID iD: https://orcid.org/0000-0002-6997-9603. E-mail: alfredocopetti@yahoo.com. 


\section{ABSTRACT}

This paper has the purpose of highlighting the importance of compliance programs in the administration, especially in municipalities, so that public governance can be accomplished. For this, deductive methodology is used through an essentially critical approach, so that the concepts involving the matter, the emergence and expansion of compliance in Brazil can be analyzed, as well as its relation with public governance. In the same way, considerations will be made regarding the adoption of this mechanism by the administration, starting from laws, guidelines and examples arising from the jurisdiction of the Union and the States. From that, the idea is to evidence the instruments of the compliance programs in the public sector and its fundamental application for greater effectiveness and improvement of municipal public governance. In the end, we conclude to be fundamental and positive the application of compliance programs as a tool for effectiveness of public governance in municipalities, especially because it has the consequence of reducing risks to the administration and the fact of present itself as an essential mechanism for greater ethics and efficiency in the public sector.

Keywords: Municipal Public Administration. Compliance. Governance. Integrity.

\section{INTRODUÇÃO}

A rejeição à falta de ética no setor público e privado tem sido crescente, em especial a partir das divulgações de numerosos escândalos de corrupção e outros ilícitos e da decorrente publicidade dada pela mídia a esses eventos. Por consequência, a corrupção atrai cada vez mais a atenção da sociedade, seja no cenário nacional ou internacional, exigindo união de esforços para combatê-la.

Segundo o Índice de Percepção da Corrupção, criado pela Transparência Internacional, organização não governamental com sede em Berlim, na Alemanha, e considerado o principal indicador de corrupção no setor público do mundo, o Brasil atingiu sua pior posição na série histórica, com a posição de n 106 entre 180 países no ano de 2019. A nota do país foi de 35 pontos em uma escala que vai de 0 (altamente corrupto) a 100 (muito íntegro). ${ }^{3}$

Tal colocação é um exemplo preocupante, mas que demonstra os motivos da crescente busca de aprimoramento da governança pública e das ferramentas de combate à corrupção, seja por parte da administração pública, das entidades privadas, seja por parte da doutrina, que cada vez tem dedicado maior espaço a esses estudos.

Com base nisso, o presente artigo tem como foco a necessidade de compreensão do compliance como ferramenta de combate à corrupção, especialmente no âmbito da governança pública municipal, com o objetivo de contribuir para o seu aprimoramento.

O Brasil possui uma enorme quantidade e diversidade de municípios, nos quais a estrutura e capacidade para controlar a corrupção e outros ilícitos geralmente diferem em amplo espectro.

Para realizar a investigação dessa problemática, utiliza-se do método de abordagem dedutivo, com técnica essencialmente crítica, por meio de pesquisa exploratória, descritiva e explicativa, fundada basicamente em legislação, doutrina e pesquisa documental, para des-

3 Para mais informações sobre o Índice de Percepção da Corrupção, cf. TRANSPARÊNCIA INTERNACIONAL. Índice de Percepção da Corrupção 2019: Transparência Internacional Brasil, 2020. Disponível em: https://transparenciainternacional.org.br/ ipc/. 
tacar a importância que os programas de compliance têm na busca por uma governança pública mais íntegra e efetiva nos municípios.

Sendo assim, buscar-se-á verificar de que forma esse aprimoramento tem sido feito e quais são os possíveis caminhos para o seu sucesso, a partir de orientações de órgãos como a Controladoria-Geral da União - CGU, bem como os exemplos dos demais entes da federação que podem servir de modelo aos municípios para uma melhor formulação dos programas de compliance, que levem ao alinhamento com os objetivos da governança pública. Ao final, buscar-se-á responder se os programas de compliance contribuem para a melhoria da governança pública municipal, e de que forma devem ser instituídos para o alcance desse objetivo.

\section{OS PROGRAMAS DE COMPLIANCE E A GOVERNANÇA PÚBLICA}

A expansão de uma verdadeira cultura pela integridade nas empresas e organizações, e, mais recentemente, no setor público, encontrou guarida nos programas de compliance, que começaram a ser instituídos no Brasil, principalmente após o surgimento da Lei Anticorrupção (Lei $n^{\circ} 12.846 / 2013$, regulamentada pelo Decreto $\left.n^{\circ} 8.420 / 2015\right)$, e da Lei das Estatais (Lei $n^{\circ} 13.303 / 2016$, regulamentada pelo Decreto $\left.n^{\circ} 8.793 / 2016\right)^{4}$.

A palavra compliance tem sua origem do verbo da língua inglesa to comply, que expressa, em sentido expandido, um estado de estar de acordo com certas diretrizes ou normas estabelecidas, sejam especificações ou a legislação. Já o termo integridade, muitas vezes usado como sinônimo desse, pode ser estabelecido como um valor essencial que é causa de existir do programa de compliance, que não apenas o orienta, mas que é um elemento fundamental de todo um sistema de integridade. (OLIVEIRA; ACOCELLA, 2019, p. 81).

Na prática, os programas de compliance, como técnica, não são apenas um adereçamento organizado dos sistemas de auditoria interna ou de arbitragem, pois vão muito além, revelando-se como uma espécie de aceite institucional guiado pela finalidade preventiva, programado por uma série de condutas destinadas a reduzir os riscos da atividade, e que engloba as diversas perspectivas decisórias do âmbito empresarial. (SILVEIRA; SAAD-DINIZ, 2015 , p. 255)

Surgido nos Estados Unidos, o compliance se tornou relevante principalmente após o surgimento do FCPA - Foreign Corrupt Practices Act, no ano de 1977, que sistematizou o controle de cometimento de atos de corrupção por empresas americanas no exterior. (SPORKIN, 1997, p. 271-272). Ainda, sua jurisdição é capaz de abarcar indivíduos de qualquer outro país que utilizem meios situados em território norte-americano para realizar atos de corrupção. (VENTURINI; CARVALHO; MORELAND, 2019, p. 319).

4 Apesar do crescimento dos programas ter sido considerável após a criação das normativas mencionadas, o compliance no Brasil surgiu inicialmente por consequência da Lei $n^{\circ}$ 9.613/1998, que dispõe sobre os crimes de lavagem de dinheiro, ao estabelecer, nos seus artigos $9^{\circ}, 10^{\circ}$ e $11^{\circ}$, o dever de informação por parte das instituições financeiras às autoridades competentes, sob pena de responsabilização. 
As disposições antissuborno do Foreign Corrupt Practices Act - FCPA incluem a proibição de pagar, oferecer ou prometer pagar a funcionários de governos estrangeiros para influir em qualquer ato estatal, ou influenciar funcionários a agir ou deixar de agir em contrariedade à sua obrigação legal, ou induzir o uso de sua influência perante o governo para o ganho de negócios. (GLYNN; KOBRIN; NAÍM, 1997, p. 18).

Contudo, a adoção pioneirista pelos Estados Unidos de punir a corrupção transnacional terminou por criar um sentimento de disparidade de negócios nos altos comandos executivos das empresas norte-americanas. Ocorre que nenhum outro país industrializado havia promulgado ou feito cumprir normas semelhantes, e, especialmente nas décadas de 1980 e 1990, o Foreign Corrupt Practices Act - FCPA se manteve como um ponto bastante sensível e polêmico para a comunidade empresarial norte-americana, especialmente porque os seus negócios no exterior passaram a corresponder a uma parcela crescente das receitas dessas corporações. (GLYNN; KOBRIN; NAíM, 1997, p. 18).

Levando em conta as suas diversas visões acerca do Foreign Corrupt Practices ActFCPA, os executivos das multinacionais norte-americanas foram quase unânimes no seu interesse por uma maior igualdade de condições, de forma que promoveram o encorajamento para que o governo dos Estados Unidos atuasse para que previsões da norma fossem internacionalizadas ou mesmo para persuadir outros países a adotarem leis semelhantes. (GLYNN; KOBRIN; NAÍM, 1997, p. 19).

Essas condições foram fundamentais para que o governo norte-americano aumentasse a pressão para que recomendações antissuborno fossem aprovadas por organizações internacionais e pelos países que delas participavam. No ano de 1994, dois fatores foram fundamentais quando da produção, pela Organização para a Cooperação e Desenvolvimento Econômico - OCDE, de recomendações contra corrupção internacional: a pressão do governo norte-americano por ações mais serias contra o suborno, bem como um sentimento anticorrupção que existia na Europa, o que tornou cada vez mais difícil para os governos europeus se oporem publicamente à iniciativa dos Estados Unidos. (GLYNN; KOBRIN; NAÍM, 1997, p.19-20).

O processo de globalização da economia foi, da mesma forma, fundamental ao trazer uma nova urgência à problemática. Ocorre que esse processo de integração econômica fez crescer a probabilidade de que os impactos da corrupção se ampliassem e terminassem por influenciar toda a economia global, de forma que a globalização ao facilitar a ocorrência da corrupção, também serviu para evidenciá-la e combate-la. (GLYNN; KOBRIN, NAÍM, 1997, p. 12-13).

Justamente em decorrência dessa nova preocupação com a corrupção e do contexto histórico envolvido, diversos foram os compromissos internacionais assumidos pelo Brasil, como, por exemplo, a Convenção Interamericana Contra a Corrupção, internalizada no ordenamento brasileiro a partir do Decreto $n^{\circ} 4.410$, de 7 de outubro de 2002 (BRASIL, 2002, online), a Convenção da Organização das Nações Unidas contra a Corrupção, internalizada por meio do Decreto n 5.687, de 31 de janeiro de 2006 (BRASIL, 2006, online) e a Convenção sobre o Combate à Corrupção de Funcionários Públicos Estrangeiros em Transações Comerciais Internacionais, da Organização para Cooperação e Desenvolvimento Econômico - OCDE, internalizada por meio do Decreto $n^{\circ} 3.678$, de 30 de novembro de 2000. (BRASIL, 2000, online). 
A Convenção Interamericana contra a Corrupção, da Organização dos Estados Americanos - OEA, teve por finalidade provocar a consciência coletiva para a gravidade do problema existente, de forma a incentivar ações de combate à corrupção transnacional entre os Estados, e se direcionar especialmente à prevenção, detecção e sanção da corrupção na função pública e às atividades a ela relacionadas. (BLOK, 2014, posição 747).

Susan Rose-Ackerman (2001, p. 255), uma das pesquisadoras mais eloquentes sobre o tema, afirma que "a Convenção exige bom grau de cooperação fronteiriça e demanda aos países que proíbam e punam os subornos internacionais."

Da mesma forma, o Brasil aderiu às diretrizes na Parceria para o Governo Aberto ou OGP - Open Government Partnership, iniciativa que congrega nações e organizações da sociedade civil na busca pelo fortalecimento das democracias e na luta contra a corrupção, entre outros. (CGU, [2020b?]).

Houve, portanto, a partir dos próprios compromissos internacionais assumidos, o direcionamento para que o Brasil passasse a adotar novas ferramentas no combate à corrupção e outros ilícitos, assim como para o fortalecimento da democracia constitucional (COPETTI NETO, 2016, passim) e da governança pública.

A governança, primeiramente, teve origem no âmbito corporativo, e se relacionou ao momento histórico no qual as organizações empresariais se afastaram do modelo clássico de gestão pelo proprietário e se moveram para uma administração por terceiros, que receberam o poder e a autoridade para o gerenciamento da empresa. Por muitas vezes, porém, as discordâncias entre esses novos administradores e os proprietários acabou por gerar conflitos de interesses, de forma que cada parte tinha como mote obter o máximo de benefício próprio. (TCU, 2014, p. 11).

Acontece que a governança corporativa é um conceito difuso, que não necessariamente deve ser aplicado única e exclusivamente à gestão empresarial, mas que pode ser utilizado para preservação do meio ambiente, como governança ambiental, bem como ao combate ao suborno e à corrupção na função pública, no caso da governança pública. (MAZALLI; ERCOLIN, 2018, p. 16 apud Alves, 2001).

A governança pública, portanto, teve sua origem da ideia de governança corporativa, e pode ser entendida como um sistema que define o equilíbrio de poder entre os cidadãos, os governantes, a alta administração, os gestores e os colaboradores, com a finalidade de possibilitar a prevalência do bem comum sobre interesses individuais ou de grupos. (TCU, 2014, p. 17-18 apud MATIAS-PEREIRA, 2010, adaptado).

Ocorre que a crise fiscal dos anos 1980 exigiu novo arranjo econômico e político internacional, com a intenção de tornar o Estado mais eficiente. (TCU, 2014, p. 13). Esse contexto promoveu a discussão da governança pública, que, de acordo com o International Federation of Accountants - IFAC, é regida pelos princípios da transparência (openness), integridade (integrity) e prestação de contas ${ }^{5}$ (accountability). (IFAC, 2001, p. 20).

5 No presente artigo, será utilizado o termo 'prestação de contas' como tradução do termo de origem na língua inglesa accountability, conforme o Referencial de Governança do TCU (2014, p. 13). Isso pois a tradução do termo para língua portuguesa e sua definição ainda são objeto de debate doutrinário no Brasil. Cf. CAMPOS, Anna Maria. Accountability: quando poderemos traduzi-la para o português? Revista de Administração Pública, Rio de Janeiro, fev./abr. 1990; Cf. DE PINHO, José Antonio Gomes; SACRAMENTO, Ana Rita Silva. Accountability: já podemos traduzi-la para o português?. Revista de Administração Pública, Rio de Janeiro, nov/dez. 2009. 
É importante destacar que, no Brasil, diversos instrumentos surgiram e continuam a emergir na busca pelo fortalecimento da governança pública, com início na década de 1990, como: a) o Código de Ética Profissional do Servidor Público Civil do Poder Executivo Federal (Decreto 1.171, de 22 de Junho de 1994); b) a Lei de Responsabilidade Fiscal (Lei Complementar 101, de 4 de maio de 2000); c) o Programa Nacional de Gestão Pública e Desburocratização (GesPública), instituído em 2005, revisado em 2009 e 2013; d) a Lei 12.813, de 16 de maio de 2013, que dispõe sobre o conflito de interesses no exercício de cargo ou emprego do Poder Executivo Federal. (TCU, 2014, p. 15).

Merecem especial destaque, porém, as definições trazidas pelo Decreto n 9.203/2017 BRASIL, 2017, online), que dispõe sobre a política de governança da administração pública federal direta, autárquica e fundacional, que são basilares e de importância fundamental para a compreensão do instituto. De acordo com o inciso I do art. $2^{\circ}$ da normativa federal, governança pública é o conjunto de mecanismos de liderança, estratégia e controle postos em prática para avaliar, direcionar e monitorar a gestão, com vistas à condução de políticas públicas e à prestação de serviços de interesse da sociedade. Os princípios da governança pública, por sua vez, nos termos do art. $3^{\circ}$, serão a capacidade de resposta, a integridade, a confiabilidade, a melhoria regulatória, a prestação de contas e a responsabilidade, assim como a transparência.

0 art. $4^{\circ}$ do Decreto n 9.203/2017 (BRASIL, 2017, online) estabelece ainda uma série de diretrizes para governança pública, destacando-se o inciso $\mathrm{V}$, que trata da previsão de fazer incorporar padrões elevados de conduta pela alta administração para orientar o comportamento dos agentes públicos, bem como do inciso $\mathrm{VI}$, que dispõe da necessidade de implementação de controles internos fundamentados na gestão de risco, que deverá privilegiar ações estratégicas de prevenção antes de processos de sanção.

Deve-se destacar também a definição trazida no inciso III do art. $5^{\circ}$ do referido Decreto (BRASIL, 2017, online), que prevê o controle como mecanismo de governança pública e que compreende processos estruturados para mitigar riscos, visando o alcance dos objetivos institucionais, a fim de garantir a execução ordenada, ética, econômica, eficiente e eficaz das atividades da organização, com preservação da legalidade e da economicidade no dispêndio de recursos públicos.

Já no seu artigo 19, o Decreto n 9.203/2017 prevê expressamente a adoção de programas de integridade pelos órgãos e entidades da administração pública direta, autárquica e fundacional:

Art. 19. Os órgãos e as entidades da administração direta, autárquica e fundacional instituirão programa de integridade, com o objetivo de promover a adoção de medidas e ações institucionais destinadas à prevenção, à detecção, à punição e à remediação de fraudes e atos de corrupção, estruturado nos seguintes eixos:

I - comprometimento e apoio da alta administração;

II - existência de unidade responsável pela implementação no órgão ou na entidade; III - análise, avaliação e gestão dos riscos associados ao tema da integridade; e

IV - monitoramento contínuo dos atributos do programa de integridade. 
É possível compreender, portanto, a relação entre o compliance e a governança pública, pois os eixos e diretrizes de ambos se encontram alinhados e se complementam, conforme deixa claro o Decreto $n^{\circ} 9.203 / 2017$, bem como a finalidade a qual se destinam, que é o cumprimento ético e eficiente das atividades da organização, a preservação da legalidade e redução de riscos à administração. (BRASIL, 2017, online).

A importância da relação entre a governança pública e os eixos dos programas de compliance pode ser destacada também pelo entendimento organizações como o Independet Comission for Good Governance in Public Services - ICGGPS, o Banco Mundial e o Institute of Internal Auditors - IIA, que entendem que, para mais bem servir ao interesse público, é fundamental que o comportamento ético, íntegro, responsável, comprometido e transparente de liderança seja garantido, bem como que: a) a corrupção seja controlada; b) que um código de ética e conduta seja efetivamente implementado; c) que se observe e garanta que as organizações aderem às regulamentações, normas, códigos e padrões; d) que as comunicações sejam transparentes e efetivas; e) que os interesses sejam equilibrados e abranjam efetivamente os stakeholders (sejam cidadãos, usuários dos serviços, iniciativa privada ou acionistas. (TCU, 2014, p. 13).

A previsão de padrões elevados de conduta para os membros da administração, bem como a existência de mecanismos de controle para redução de riscos e a consequente implementação de controles internos são fundamentais, portanto, na construção de uma governança pública efetiva. Esses também são pilares dos programas de compliance, conforme visto anteriormente, e devem ser implementados para o aprimoramento da governança pública.

Apresentados tais conceitos, deve-se analisar a efetividade e importância dos programas de compliance público, mais especificamente no âmbito municipal, bem como quais são as orientações básicas para sua implementação, para que se possa avançar em direção a uma administração pública mais ética e íntegra que esteja de acordo com os preceitos de melhor governança pública.

\section{OS PROGRAMAS DE COMPLIANCE EM ÂMBITO MUNICIPAL E AS ORIENTAÇÓES DA CGU}

Uma vez demonstrada a notável ligação entre a governança pública e o compliance, é importante destacar como a atuação da Controladoria-Geral da União - CGU tem sido fundamental no processo de expansão desses institutos nos municípios, bem como para seu aprimoramento.

A partir de iniciativas como a Coleção Município Transparente, o órgão propõe aos Municípios desde sugestões de regulamentação via Decreto da Lei Anticorrupção (Lei $n^{\circ}$ 12.846/2013) a guias de fortalecimento da gestão, assim como orientações para implementação de corregedorias municipais. (CGU, 2017, online).

A atuação da Controladoria-Geral da União - CGU na aplicação da lei anticorrupção é crucial, pois, sem sombra de dúvidas, é o órgão que apresenta melhor estrutura e se mostra 
mais hábil para essa função, uma vez que possui competência e capacitação para tanto, bem como pelo fato de que seus funcionários detém experiência e conhecimento do que é um compliance que seja efetivo, havendo participado de fóruns e grupos internacionais, inclusive na Organização para Cooperação e Desenvolvimento Econômico - OCDE. (BLOK, 2014, posição 1213).

Especificamente no Guia Como Fortalecer sua Gestão, o órgão orienta os entes e órgãos públicos municipais especialmente a: 1) regulamentar a Lei Anticorrupção no âmbito municipal; 2) cadastrar o órgão ou ente público no Sistema Integrado de Registro do Cadastro Nacional de Empresas Inidôneas e Suspensas - CEIS e no Cadastro Nacional de Pessoas Punidas - CNEP; 3) incentivar a adoção de programas de integridade por parte das pessoas jurídicas que se relacionam com seu órgão ou ente e 4) promover a capacitação, de forma a assegurar o conhecimento da legislação por parte dos servidores ou gestores públicos. (CGU, 2017, online).

Tais passos são básicos para que se possa consolidar a base da governança pública. Isso ocorre uma vez que sem a regulamentação da lei anticorrupção no município, ( ${ }^{\circ}$ passo da orientação da CGU no Guia Como Fortalecer sua Gestão), este ente não poderá reprimir eventuais ilícitos cometidos. A regulamentação estabelece a normativa legal e amplia as formas pelas quais a administração pública pode fiscalizar e punir, de forma adequada, condutas ilícitas e antiéticas.

O gestor municipal deverá, ainda, incluir o ente público e seus órgãos nos cadastros do Cadastro Nacional de Empresas Inidôneas e Suspensas - CEIS e no Cadastro Nacional de Pessoas Punidas - CNEP ( $2^{\circ}$ passo da orientação da CGU no Guia de Fortalecimento de Gestão), para que assim possam ser incluídos no sistema nacional as punições derivadas da regulamentação da Lei Anticorrupção.

A aplicação da lei, ainda, exigirá da administração pública municipal capacitação e órgãos preparados para exercer tal função. A criação de um órgão, como uma Corregedoria, por exemplo, poderá fazê-lo responsável por propagar conhecimento, ao promover treinamento e capacitação aos servidores públicos, para que estes tenham conhecimento da lei e estejam preparados para aplicá-la, conforme recomenda a Controladoria-Geral da União no $4^{\circ}$ passo da orientação no Guia Como Fortalecer sua Gestão. (CGU, 2017, online).

Já com relação à adoção de programas de integridade por pessoas jurídicas que se relacionem com o ente municipal, $3^{\circ}$ passo da orientação da Controladoria-Geral da União CGU no Guia de Fortalecimento de Gestão, estes podem ser incentivados a partir da adoção obrigatória de programa de compliance no âmbito das contratações públicas, o que será, por sua relevância, objeto de destaque nos capítulos seguintes do presente artigo. (CGU, 2017, online).

É fundamental, ainda, para a efetividade dos programas de compliance na administração pública, a adoção dos códigos de conduta, cuja função se mostra indispensável para a formação de uma cultura de cumprimento das regras. Esses códigos devem abranger diversas situações da vida cotidiana, mas devem contar com canais de denúncia efetivos e que protejam a identidade dos denunciantes, de modo que não ocorra contra eles qualquer tipo de represália (CARVALHO et al., 2019, p. 648). A União, a título de exemplo, adota o Código de Conduta da Alta Administração Federal, no qual busca velar por elevado padrão de com- 
portamento ético de seus servidores, que possam garantir a lisura e transparência dos atos praticados na condução da coisa pública. (BRASIL, 2000, online).

Além disso, ao definir quais são as condutas vedadas, busca garantir aos agentes públicos maior segurança ao indicar quais as limitações de seus atos, assim como possibilita aos órgãos de controle dentro da administração pública municipal a base para apuração de potenciais práticas não permitidas.

O código de conduta deve, então, estabelecer de que forma o agente deve se comportar, assim como as empresas que se relacionam com o poder municipal, impondo, propriamente, as políticas destinadas a esses fundamentais partícipes nas relações público-privadas. Porém, os códigos de conduta apenas serão efetivos caso realmente reflitam o que ocorre dentro do âmbito administrativo, com destaque para a necessidade conjunta de um canal de denúncias, que ocupa papel fundamental para a efetividade das normas nele descritas e do próprio programa de integridade. (CARVALHO et al., 2019, p. 650).

O papel do canal de denúncias é essencial, pois será este que receberá os relatos de possíveis atos de corrupção, condutas antiéticas ou práticas que atentem contra o código de conduta, o que pode se dar através de um ou mais sistemas, como telefone, e-mail, internet ou intranet.

Deve-se ter atenção para que o canal de denúncias não afaste possíveis colaboradores preocupados com algum tipo de represália no âmbito público municipal, como a abertura de processos administrativos disciplinares, o que provavelmente desencorajaria o relato das irregularidades.

Sendo assim, é importante também a criação de mecanismos de proteção aos denunciantes que busque dar efetividade ao canal de denúncias, para garantir-lhe real aplicabilidade e funcionamento. Nesse sentido, tem-se o exemplo do Decreto no 10.153/2019, do Governo Federal, que estabelece salvaguardas de proteção a denunciantes de ilícitos e de irregularidades praticados contra a administração pública federal. (BRASIL, 2019, online). Tal salvaguarda é essencial, pois de nada serviria que se possua o melhor canal de denúncias disponível, mas que por trás deste não existam medidas adequadas que salvaguardem o denunciante, colocando-o à mercê de possíveis retaliações.

Conforme demonstrado, seja com base na normativa legal ou nas orientações da Controladoria-Geral da União - CGU, apenas haverá verdadeira efetividade de um programa de compliance, com base na governança pública, em âmbito municipal, caso sua implementação seja real, de forma que deve possuir os mecanismos necessários para que exista efetividade no plano material. Para isso, além de regulamentar a lei anticorrupção, os municípios deverão incluir as empresas nos cadastros do Sistema Integrado de Registro do Cadastro Nacional de Empresas Inidôneas e Suspensas - CEIS e no Cadastro Nacional de Pessoas Punidas - CNEP, assim como promover a capacitação de agentes públicos, elaborar um código de conduta e estabelecer um canal de denúncias, além de incluir normas com relação à adoção de programas de compliance por empresas que se relacionam com a administração pública, o que será analisado a seguir. 


\section{A EXIGÊNCIA DE PROGRAMAS DE COMPLIANCE PARA AS CONTRATAÇÓES PÚBLICAS}

A exigência pela adoção de programas de compliance por empresas que se relacionam com a administração pública, especialmente nos processos de contratações, surgiu por iniciativa do Estado do Rio de Janeiro (Lei $n^{\circ}$ 7.753/17) e do Distrito Federal (Lei nº 6.112/18). A inovação tem se multiplicado e já é adotada por outros estados da federação, bem como se expandiu a diversos municípios brasileiros ${ }^{6}$.

Nesse sentido, importa analisar o compliance no âmbito das contratações públicas, relatar de que forma as iniciativas dos entes estaduais tem sido reproduzidas pelos municípios, bem como destacar a importância de que estes entes cumpram as recomendações da Controladoria-Geral da União - CGU para que, a partir da formulação correta dos programas, seja garantida maior efetividade à governança pública municipal.

\subsection{CONTEXTO}

Conforme retratado, o combate à corrupção e outros ilícitos, através da governança pública, tem deixado a esfera do Governo Federal para se expandir aos Estados e Municípios, de forma que muitos já exigem que empresas ou organizações que se relacionem com o poder público implementem programas de compliance.

Discussões se apresentam na doutrina com relação a possíveis vícios de inconstitucionalidade que as normas de exigência de programas de compliance nas licitações e contratações públicas poderiam trazer. (CASTRO; ZILIOTTO, 2019, p. 22).

A exigência de compliance nas contratações não é inconstitucional, uma vez que não conflita com o previsto no inciso XXI do art. 37 da Constituição da República, nem com as normas estabelecidas pela Lei Geral das Licitações ( $n^{\circ}$ 8.666/1993), mas que, na verdade, as complementa, alinhando-se às necessidades de cada ente. (CASTRO; ZILIOTTO, 2019, p. 43).

Ocorre que a própria Constituição da República, no seu artigo 37, define o princípio da moralidade como regente da atividade administrativa. A Lei Federal n 8.666/1993, relativa às licitações, traz, da mesma maneira, no seu artigo $3^{\circ}$, o princípio da moralidade como um dos pilares da administração. A norma estabelece, no mesmo sentido, de que a promoção do desenvolvimento nacional sustentável é um dos objetivos da licitação. (CASTRO; ZILIOTTO, 2019, p. 25-26).

Parte desse raciocínio surge do fato de que é possível o desenvolvimento de políticas sociais de interesse público por parte do Estado, mesmo nas contratações, desde que autorizado pela ordem legal. (GUIMARÃES; REQUI, 2018, p. 207).

Ocorre que, como o direito administrativo é responsável por conduzir a atuação pública e por estabelecer os padrões dentro do qual o poder público deve atuar em direção à finalidade orientada pela Constituição, é de importância fundamental que esteja delimitado com

6 Ver projeto de Lei n. 16/20 de Cascavel-PR, que estabelece uma série de requisitos à contratação com o Poder Público. 
uma pluralidade de temas que busque assegurar uma atuação eficaz. (DIAS; COIMBRA, 2019, p. 4).

No caso das licitações, porém, deve-se ter o cuidado de que não exista ofensa ou entrave à participação na concorrência, o que desrespeitaria o disposto no inciso XXI do artigo 37 da Constituição da República de 1988.

Não existe violação caso o requisito não trate da condição de habilitação, o que levaria à inconstitucionalidade, mas sim de obrigação contratual, de forma que os programas de compliance somente deveriam ser exigidos na terceira fase da contratação, quer dizer, na execução do contrato administrativo. (DE CASTRO; ZILIOTTO, 2019, p. 44).

Por sua vez, tais vícios apenas podem ser devidamente analisados caso a caso, em cada legislação, a partir de uma observação detida e da semântica da redação legal. (LOSINSKAS; FERRO, 2019, p. 671).

O que as exigências de programas de integridade nas contratações pública pretendem, na verdade, é a redução dos riscos para a administração pública, especialmente com relação a prejuízos econômicos derivados da corrupção, como conluios ou cartéis. (GUIMARÃES; REQUI, 2018, p. 208).

Mostra-se, assim, positiva a movimentação dos entes estaduais e municipais contra os ilícitos como corrupção e outros desvios, principalmente ao exigir programas de integridade que combatam condutas antiéticas ou ilegais, justamente ao almejar a sua redução e, ao mesmo tempo, na busca de concretizar os princípios norteadores da administração pública, quais sejam a legalidade, a impessoalidade, a moralidade, a publicidade a eficiência, previstos no artigo 37 da Constituição da República. (BRASIL, 1988, online). Ao mesmo tempo, as iniciativas atendem à recomendação da Controladoria-Geral da União no item 3) do Guia Como Fortalecer sua Gestão (CGU, 2017, online), que é incentivar a adoção de programas de integridade por parte das pessoas jurídicas que se relacionam com seu órgão ou ente, conforme visto anteriormente.

Certo é, a todo modo, que as legislações estaduais e municipais têm tomado a iniciativa legal de exigir programas de compliance para as contratações públicas na pretensão de aprimoramento da governança pública. (LOSINSKAS; FERRO, 2019, p. 671).

Interessa, consequentemente, verificar de que modo a exigência de programas de compliance nas licitações e contratações públicas tem sido feita e como pode ser aprimorada, para que, ao final, se atinja a sua finalidade inicial, qual seja, a busca da redução de atos de corrupção e outros ilícitos na administração pública.

\subsection{OS CRITÉRIOS DE EXIGÊNCIA NOS ESTADOS E O SEU SURGIMENTO NOS MUNICÍPIOS}

Não existe, até o presente momento, normativa federal que obrigue as organizações privadas a implementar programas de compliance para as contratações públicas, de forma que as leis estaduais são os principais pontos de referência para os municípios. 
Atualmente, pelo menos sete Estados possuem leis ou decretos que obrigam os contratantes com a administração pública a estabelecerem um programa de compliance. (DE FARIA; CHIZZOTTI, 2020, online).

Apesar do Estado do Rio de Janeiro (2017, online) ter sido pioneiro no Brasil, ao dispor, a partir da Lei $n^{0} 7.753 / 17$, da obrigatoriedade de programas de compliance para as empresas que têm relações com a administração pública, importa, aqui, analisar a normativa do Distrito Federal, especialmente pela natureza mista de ente estadual e municipal, este último como foco do presente artigo, não com objetivo de exauri-la, mas apenas de exemplificar os critérios adotados por ela.

A partir da Lei $n^{\circ} 6.112 / 18$, o Distrito Federal (2018, online) estabeleceu a obrigatoriedade dos programas de integridade para contratações, para todas as esferas de poder, desde que os valores sejam superiores para contratação na modalidade tomada de preços, que está prevista na Lei $n^{\circ} 8.666 / 1993$, e desde que o contrato apresente prazo superior a 180 (cento e oitenta) dias. (DE CASTRO; ZILIOTTO, 2019, p. 37). Inicialmente, a norma previu que os valores sejam iguais ou superiores aos da licitação na modalidade tomada de preço, estimados entre $\mathrm{R} \$ \mathbf{8 0 . 0 0 0 , 0 0}$ (oitenta mil reais) e $\mathrm{R} \$ \mathbf{6 5 0 . 0 0 0 , 0 0}$ (seiscentos e cinquenta mil reais), ainda que na forma de pregão eletrônico. Contudo, após alteração legislativa no ano de 2019, a normativa do Distrito Federal (2018, online) passou a prever que a obrigatoriedade se aplicaria a valores superiores a $\mathrm{R} \$ 5.000 .000,00$ (cinco milhões de reais).

Importa ressaltar que a normativa distrital igualmente dispôs com relação à metodologia de avaliação dos programas de compliance, ao enfatizar que não serão aceitos os programas de fachada ou scham programs, aqueles meramente formais mas que, a bem da verdade, mostram-se ineficazes para reduzir o risco de ocorrência de atos lesivos contra a administração pública previstos na lei. (CARVALHO; VENTURINI, 2018, online).

Pois bem, a partir do exemplificado pela norma do Distrito Federal, nota-se que o ente municipal deve definir, pelo menos, os seguintes critérios: a) o prazo mínimo de contrato, b) o valor mínimo da contratação e c) como se dará a avaliação dos programas de compliance.

Isso ocorre porque o estabelecimento de um programa de compliance é complexo, muitas vezes exigindo prazo inclusive maior do que cento e oitenta dias, como prevê a Lei do Distrito Federal (2018, online). O município que pretenda regulamentar a exigência de compliance para contratações públicas, deve, portanto, levar esse critério em consideração, sob pena de que muitas empresas acelerem o estabelecimento desses programas para cumprir os prazos contratuais, sem considerar, de fato, sua real efetividade ou adequação, criando verdadeiros scham programs.

No caso da avaliação dos programas de compliance, especialmente nas exigências posteriores à celebração do contrato, o método avaliativo, que pode se dar por meio de certificações, tem como finalidade assegurar ao poder público sua real efetividade, a fim de evitar, justamente, um scham program.

O elemento central do debate a favor da avaliação dos programas de compliance por meio de certificação encontra base no fato de que pode se mostrar excessivamente dificultoso para a administração pública, no momento de avaliação desses programas, fazê-lo com a análise técnica adequada. Ocorre que, por muitas vezes, inexiste, na administração pública, agentes públicos preparados em número suficiente para poder cumprir esse papel. É por essa 
razão, também, que os órgãos municipais encarregados pelo controle da lei anticorrupção e fiscalização dos contratos devem contar com servidores treinados e qualificados, conforme a recomendação da Controladoria-Geral da União no item 4) no seu Guia de Fortalecimento de Gestão, que é a de promover a capacitação, de forma a assegurar o conhecimento da legislação por parte dos servidores ou gestores públicos. (CGU, 2017, online).

Importante ressaltar que, até o presente momento, inexiste normativa ou referência de qual, ou quais, seriam as certificações mais adequadas, o que se encontra em debate perante a doutrina e órgãos do Governo.

Certificação bastante reconhecida internacionalmente é a ISO 37001, que trata de sistemas de gestão antissuborno, aprovada em $2016 \mathrm{com}$ a participação do Brasil, por meio da Associação Brasileira de Normas Técnicas. (ABNT, 2017, p. 6). Por sua vez, a iniciativa Empresa Pró-Ética, da Controladoria-Geral da União (CGU, [2020a?], online), que consiste em fomentar a adoção voluntária de medidas de integridade pelas empresas, por meio do reconhecimento público daquelas que, independentemente do porte e do ramo de atuação, mostram-se comprometidas em implementar medidas voltadas para a prevenção, detecção e remediação de atos de corrupção e fraude.

Por óbvio, a questão da avaliação centralmente abrange todo o funcionamento do programa de compliance e da redução de riscos para a administração pública. Sendo assim, se adotado, é primordial que o método avaliativo seja adequado, e que tal seja previsto na lei ou em regulamentação específica municipal.

Ainda, deve ser considerado: qual é o valor razoável para a exigência de compliance? Essa pode ser a questão de maior dificuldade de resposta. Para isso, parece ser mais razoável que seja apreciado, pelo município regulamentador, qual seria o valor adequado de acordo com realidade local, assim como das empresas que com o ente negociam. A importância dessa consideração é fundamental, pois não parece equilibrado exigir um programa de compliance robusto de uma empresa que contrate por valores baixos, o que pode levar a distorções dos processos licitatórios e à eliminação de concorrência. Deve considerar-se o porte e as especificidades da pessoa jurídica, com a finalidade de evitar deturpações, conforme também dispõe o $\S 1^{\circ}$ do artigo $6^{\circ}$ da norma do Distrito Federal. (2018, online).

A partir, portanto, das normativas estaduais e de seus aperfeiçoamentos, muitas têm sido as iniciativas dos poderes executivo e legislativo municipais com relação à exigência de tais programas. Cidades de importância relevante em seus Estados aderiram a projetos para implementação do compliance público. Cita-se a título de exemplo os casos de Jaraguá do Sul/SC (2019, online), através do Decreto $n^{\circ} 12.533$, Foz do Iguaçu/PR (2019b, online), pela Lei Municipal nº 4.832 e Ponta Grossa/PR (2019, online), pelo Decreto nº 15.520.

Já com relação à exigência de programas de compliance para contratar com a administração, houve adoção pela cidade de Vila Velha - Espírito Santo (2018, online), com a Lei nº 6.050. Na cidade de Foz do Iguaçu/PR (2019a, online), já existe projeto de lei nesse sentido (Projeto de Lei $n^{\circ} 172$ ).

É possível verificar, de todas essas iniciativas, que a pretensão ao adotar os programas de compliance é realmente estabelecer um meio para mudança da governança pública e da cultura empresarial, e espera-se que a crescente rejeição à corrupção e outras irregularidades no setor público continuem a inspirar diversas iniciativas e projetos de lei em muitos 
dos 5.576 municípios brasileiros (IBGE, 2017, online), de forma a seguir a tendência de adequação aos melhores padrões de governança pública a partir da criação de programas de compliance adequados.

\section{CONSIDERAÇÓES FINAIS}

É notável que as inovações introduzidas, nos últimos anos, ao ordenamento jurídico do país, assim como compromissos internacionais assumidos pelo Brasil, buscam promover a disseminação da ética e da integridade, tanto no setor público como no setor privado.

É a partir dessa nova conjuntura que a governança pública se ergue, apoiada no compliance, que tem se apresentado como mecanismo essencial na construção de uma nova governança pública, mais ética e eficiente, não só como boa prática, mas como uma necessidade que vai ao encontro dos princípios administrativos estabelecidos pela ordem constitucional.

Os programas de compliance buscam a redução dos riscos de malfeitos para a administração pública, como atos de corrupção e outros desvios em licenças, contratações publicas, entre outros. Por isso, tais iniciativas têm sido replicadas. No âmbito da União, destaca-se o importante papel orientativo da Controladoria-Geral da União - CGU, merecedor de destaque. É extremante importante, conforme recomenda esse órgão, que os municípios regulamentem a lei anticorrupção no âmbito municipal, cadastrem o órgão ou ente público no Sistema Integrado de Registro do Cadastro Nacional de Empresas Inidôneas e Suspensas - CEIS e no Cadastro Nacional de Pessoas Punidas - CNEP, incentivem a adoção de programas de integridade por parte das pessoas jurídicas que se relacionam com seu órgão ou ente e promovam a sua capacitação, de forma a assegurar o conhecimento da legislação por parte dos servidores ou gestores públicos. Nesse sentido, as ferramentas dos programas de compliance em âmbito municipal devem ser aplicados conjuntamente, como verdadeiros pilares, pois assim haverá realmente possibilidade de que a governança pública seja efetivada.

Especial destaque é dado ao fato de que diversos Estados têm exigido a obrigatoriedade de programas de compliance em empresas privadas para a participação em contratações públicas. Isso ocorre, principalmente, pelo fato de que as contratações públicas se mostram mais suscetíveis a condutas ilegais ou antiéticas, de forma que tem colhido especial atenção.

Restou claro, portanto, no presente trabalho, que é fundamental e positiva a adoção do compliance e de suas ferramentas na busca pela efetivação da governança pública na administração pública municipal, apresentando-se como mecanismo essencial e imprescindível para que possa ser alcançada maior ética e eficiência no âmbito público.

Não é possível, portanto, dissociar a busca por uma governança pública mais íntegra e que pretenda ser efetiva do compliance, pois este é ferramenta essencial na busca dos objetivos que devem ser almejados pela administração, de acordo com os princípios presentes na ordem legal. A adoção dos programas de compliance constitui, assim, papel essencial para a governança pública, e deve ser replicada para que se alcance uma administração mais íntegra e efetiva em benefício da sociedade. 


\section{REFERÊNCIAS}

ASSOCIAÇÃO BRASILEIRA DE NORMAS TÉCNICAS. ABNT NBR ISO 37001: 2017. ISO 37001 - Normas de Gestão Antissuborno. Rio de Janeiro, RJ: ABNT, 6 mar. 2017.

BLOK, Marcella. A Nova Lei Anticorrupção (Lei 12846/2013) e o Compliance. 1. ed. São Paulo, SP. Revista de Direito Bancário e do Mercado de Capitais, 2014. v. 65. E-book Kindle.

BRASIL. Constituição da República Federativa do Brasil de 1988. Brasília, DF: Diário Oficial da União, 5 out. 1988. Disponível em: http://www.planalto.gov.br/ccivil_03/constituicao/constituicao.htm. Acesso em: 19 maio 2020.

BRASIL. Exposição de Motivos n 37, de 21 de agosto de 2000. Código de Conduta da Alta Administração Federal. Brasília, DF: Diário Oficial da União, 22 ago. 2000. Disponível em: http://www.planalto.gov.br/ccivil_03/codigos/ codi_conduta/cod_conduta.htm. Acesso em: 19 maio 2020.

BRASIL. Decreto $n^{\circ} 3.678$, de 30 de novembro de 2000. Promulga a Convenção sobre o Combate da Corrupção de Funcionários Públicos Estrangeiros em Transações Comerciais Internacionais, concluída em Paris, em 17 de dezembro de 1997. Brasília, DF: Diário Oficial da União, 1 dez. 2000. Disponível em: http://www.planalto.gov.br/ ccivil_03/decreto/D3678.htm. Acesso em: 3 set. 2020.

BRASIL. Decreto ${ }^{\circ} 4.410$, de 7 de outubro de 2002. Promulga a Convenção Interamericana contra a Corrupção, de 29 de março de 1996, com reserva para o art. XI, parágrafo 1º, inciso "c". Brasília, DF: Diário Oficial da União, 8 out. 2002. Disponível em: http://www.planalto.gov.br/ccivil_03/decreto/2002/d4410.htm. Acesso em: 19 maio 2020.

BRASIL. Decreto $n^{\circ}$ 5.687, de 31 de janeiro de 2005. Promulga a Convenção das Nações Unidas contra a Corrupção, adotada pela Assembléia-Geral das Nações Unidas em 31 de outubro de 2003 e assinada pelo Brasil em 9 de dezembro de 2003. Brasília, DF: Diário Oficial da União, 1 fev. 2006. Disponível em: http://www.planalto.gov.br/ ccivil_03/_ato2004-2006/2006/decreto/d5687.htm. Acesso em: 2 set. 2020.

BRASIL. Tribunal de Contas da União. Referencial básico de governança aplicável a órgãos e entidades da administração pública / Tribunal de Contas da União. Versão 2 - Brasília: TCU, Secretaria de Planejamento, Governança e Gestão, 2014.

BRASIL. Instrução Normativa Conjunta $n^{\circ}$ 1, de 10 de maio de 2016. Dispõe sobre controles internos, gestão de riscos e governança no âmbito do Poder Executivo Federal. Diário Oficial da União: Seção 1, Brasília, DF, ano 128, p. 14-17, 11 maio 2016. Disponível em: http://www.in.gov.br/materia/-/asset_publisher/Kujrw0TZC2Mb/content/id/21519355/do1-2016-05-11-instrucao-normativa-conjunta-n-1-de-10-de-maio-de-2016-21519197. Acesso em: 2 mar. 2020.

BRASIL. Decreto $n^{\circ}$ 9.203, de 22 de novembro de 2017. Dispõe sobre a política de governança da administração pública federal direta, autárquica e fundacional. Diário Oficial da União: Seção 1, Brasília, DF, ano 129, p. 3-4, 23 nov. 2017. Disponível em: http://pesquisa.in.gov.br/imprensa/jsp/visualiza/index.jsp?data=23/11/2017\&jornal= 515\&pagina=3\&totalArquivos=112. Acesso em: 2 mar. 2020.

BRASIL. Decreto $n^{\circ}$ 10.153, de 3 de dezembro de 2019. Dispõe sobre as salvaguardas de proteção à identidade dos denunciantes de ilícitos e de irregularidades praticados contra a administração pública federal direta e indireta e altera o Decreto n 9.492, de 5 de setembro de 2018. Brasília, DF: Diário Oficial da União, ano 131, v. Seção 1, p. 1-2, 4 dez. 2019. Disponível em: http://www.planalto.gov.br/ccivil_03/_ato2019-2022/2019/decreto/D10153. htm. Acesso em: 5 mar. 2020.

CARVALHO, André Castro; BERTOCCELLI, Rodrigo de Pinho; ALVIM, Tiago Cripa; VENTURINI, Otavio. Manual de Compliance. $1^{\text {a }}$. ed. Rio de Janeiro: Forense, 2019. cap. 16, p. 319-348. ISBN 9788530983154.

CARVALHO, André Castro; VENTURINI, Otavio. Discussões sobre as novas regras locais de compliance nas contratações públicas. [S. I.], 5 mar. 2018. Disponível em: https://congressoemfoco.uol.com.br/opiniao/colunas/discussoes-sobre-as-novas-regras-locais-de-compliance-nas-contratacoes-publicas/. Acesso em: 4 mar. 2020.

CASTRO, Rodrigo Pironti Aguirre de; ZILIOTTO, Mirela Miró. Compliance nas contratações públicas: exigências e critérios normativos. 1. Reimpr. Belo Horizonte: Fórum, 2019. 
CONTROLADORIA-GERAL DA UNIÃO (CGU). Empresa Pró-Ética. Brasília, DF: CGU, [2020a?], Disponível em: https:// www.gov.br/cgu/pt-br/assuntos/etica-e-integridade/empresa-pro-etica. Acesso em: 2 abr. 2020.

CONTROLADORIA-GERAL DA UNIÃO (CGU). Programa de Integridade: Diretrizes Para Empresas Privadas. Brasília, DF: Controladoria-Geral da União, set. 2015. Disponível em: https://www.gov.br/cgu/pt-br/centrais-de-conteudo/publicacoes/etica-e-integridade/arquivos/programa-de-integridade-diretrizes-para-empresas-privadas. pdf. Acesso em: 2 abr. 2020

CONTROLADORIA-GERAL DA UNIÃO (CGU). Como Fortalecer Sua Gestão: Lei Anticorrupção e Programas de Integridade. Coleção Município Transparente, Brasília, DF, maio 2017. Disponível em: https://www.gov.br/cgu/pt-br/ centrais-de-conteudo/publicacoes/transparencia-publica/colecao-municipio-transparente/arquivos/como-fortalecer-sua-gestao-lei-anti-corrupcao-e-programa-de-integridade.pdf. Acesso em: 5 mar. 2020.

CONTROLADORIA-GERAL DA UNIÃO (CGU). O que é a iniciativa. [2020b?]. Disponível em: http://www.governoaberto.cgu.gov.br/dados_ogp/Ogp/a-ogp/o-que-e-a-iniciativa. Acesso em: 1 abr. 2020.

COPETTI NETO, Alfredo. A democracia constitucional sob o olhar do garantismo jurídico. Florianópolis: Empório do Direito, 2016.

DIAS, Jean Carlos; COIMBRA, Felipe Augusto Hanemann. ANÁLISE ECONÔMICA DO DIREITO ADMINISTRATIVO BRASILEIRO: CONSIDERAÇÕES SOB A PERSPECTIVA DA FORMULAÇÃO DE POLÍTICAS PÚBLICAS. Meritum: Revista de Direito da Universidade FUMEC, Belo Horizonte, MG, v. 13, n. 2, p. 420-444, Jul/Dez 2018. Disponível em: http://www.fumec.br/revistas/meritum/article/view/6570. Acesso em: 20 maio 2020.

DISTRITO FEDERAL. Lei nº 6.112, de 2 de fevereiro de 2018. Dispõe sobre a implementação de Programa de Integridade em pessoas jurídicas que firmem relação contratual de qualquer natureza com a administração pública do Distrito Federal em todas as esferas de poder e dá outras providências. Brasília, DF: Diário Oficial do Distrito Federal, 6 fev. 2018. Disponível em: http://www.sinj.df.gov.br/sinj/Norma/3bf29283d9ea42ce9b8feff3d4fa253e/ Lei_6112_02_02_2018.html. Acesso em: 4 maio 2020.

DE FARIA, Wilson; CHIZZOTTI, Camila. Obrigatoriedade de compliance para contratação pública. [S. I.]: Legis Compliance, 27 fev. 2020. Disponível em: https://www.legiscompliance.com.br/artigos-e-noticias/2106-obrigatoriedade-de-compliance-para-contratacao-publica. Acesso em: 6 maio 2020.

FOZ DO IGUAÇU. Projeto de Lei n 172/2019, de 20 de dezembro de 2019. Dispõe sobre a obrigatoriedade da implementação de "Programa de Integridade e Conformidade com as Normas" em pessoas jurídicas que firmem relação contratual de qualquer natureza com a Administração Pública no Município de Foz do Iguaçu - PR. Câmara Municipal de Foz do Iguaçu/PR, 20 dez. 2019. Disponível em: https://sapl.fozdoiguacu.pr.leg.br/materia/7792. Acesso em: 6 mar. 2020.

FOZ DO IGUAÇU. Lei n 4.832, de 20 de dezembro de 2019. Dispõe sobre a criação do Programa de Integridade e Conformidade com as Normas da Administração Pública Municipal e adota outras providências. [S. I.]: Diário Oficial do Município, 6 jan. 2020. Disponível em: https://leismunicipais.com.br/a/pr/f/foz-do-iguacu/lei-ordinaria/2019/484/4832/lei-ordinaria-n-4832-2019-dispoe-sobre-a-criacao-do-programa-de-integridade-e-conformidade-com-as-normas-da-administracao-publica-municipal-e-adota-outras-providencias. Acesso em: 15 abr. 2020.

GLYNN, Patrick; KOBRIN, Stephen J.; NAÍM, Moisés. The Globalization of Corruption. In: ELLIOTT, Kimberly Ann (ed.). Corruption and the Global Economy. $1^{\text {a }}$ ed. Washington, DC: Institute for International Economics, 1997. cap. 1, p. 7-27. ISBN 0-88132-233-4.

GUIMARÃES, Fernando Vernalha; REQUI, Érica Miranda dos Santos. Exigência de Programa de Integridade nas Licitações. In: COMPLIANCE, Gestão de riscos e Combate à Corrupção: Integridade Para o Desenvolvimento. $2^{a}$ Reimpressão. $1^{\text {a }}$ Ed. Belo Horizonte: Fórum, 2018. v. 1ํㅜ cap. 10, p. 203-215. ISBN 9788545004738.

INSTITUTO BRASILEIRO DE GEOGRAFIA E ESTATÍstICA (IBGE). Panorama Cidades. IBGE, 2 jan. 2017. Disponível em: https://cidades.ibge.gov.br/brasil/panorama. Acesso em: 4 mar. 2020.

INTERNATIONAL FEDERATION OF ACCOUNTANTS (IFAC). Governance in the Public Sector: A Governing Body Perspective. International Federation of Accountants, New York, p. 1-93, Ago. 2001. Disponível em: https://www. ifac.org/system/files/publications/files/study-13-governance-in-th.pdf. Acesso em: 2 set. 2020. 
JARAGUÁ DO SUL. Decreto n 12.533, de 25 de janeiro de 2019. Institui Comissão Especial Responsável Pela Elaboração do Programa de Integridade Pública (Compliance Público) da Administração Pública Direta do Município de Jaraguá do Sul - SC. [S. I.]: Diário Oficial do Município, 29 jan. 2019. Disponível em: https://leismunicipais. com.br/a/sc/j/jaragua-do-sul/decreto/2019/1254/12533/decreto-n-12533-2019-institui-comissao-especial-responsavel-pela-elaboracao-do-programa-de-integridade-publica-compliance-publico-da-administracao-publica-direta-do-municipio-de-jaragua-do-sul-sc. Acesso em: 18 maio 2020.

MAZALLI, Rubens; ERCOLIN, Carlos Alberto. Governança Corporativa. Rio de Janeiro: FGV Editora, 2018.

NETO, Giseppe Giamundo; DOURADO, Guilherme Afonso; MIGUEL, Luiz Felipe Hadlich. Compliance na Administração Pública. In: CARVALHO, André Castro; BERTOCCELLI, Rodrigo de Pinho; ALVIM, Tiago Cripa; VENTURINI, Otavio. Manual de Compliance. Rio de Janeiro: Forense, 2019. cap. 31, p. 645-662. ISBN 9788530983154.

OLIVEIRA, Rafael Carvalho Rezende; ACOCELLA, Jéssica. A Exigência de Programas de Compliance e Integridade nas Contratações Públicas: o Pioneirismo do Estado do Rio de Janeiro e do Distrito Federal. In: OLIVEIRA, Rafael Carvalho Rezende; ACOCELLA, Jéssica (coord.). Governança Corporativa e Compliance. Salvador: Editora JusPodivm, 2019. cap. 3, p. 71-100.

PAULA, Marco Aurélio Borges de; CASTRO, Rodrigo Pironti Aguirre de (Coord.). Compliance, gestão de riscos e combate à corrupção: integridade para o desenvolvimento. Belo Horizonte: Fórum, 2018. 452 p. ISBN 978-85450-0473-8.

PONTA GROSSA. Decreto n 15.520, de 11 de fevereiro de 2019. Institui normas para as Unidades de Gestão e Compliance - UGC da Administração Direta e Indireta do Município de Ponta Grossa. [S. I.], 12 fev. 2019. Disponível em: https://leismunicipais.com.br/a/pr/p/ponta-grossa/decreto/2019/1552/15520/decreto-n-15520-2019-institui-normas-para-as-unidades-de-gestao-e-compliance-ugc-da-administracao-direta-e-indireta-do-municipio-de-ponta-grossa?q=15.520. Acesso em: 19 maio 2020.

RIO DE JANEIRO. Lei n 7.753, de 17 de outubro de 2017. DISPÕE SOBRE A INSTITUIÇÃO DO PROGRAMA DE INTEGRIDADE NAS EMPRESAS QUE CONTRATAREM COM A ADMINISTRAÇÃO PÚBLICA DO ESTADO DO RIO DE JANEIRO E DÁ OUTRAS PROVIDENCIAS. Rio de Janeiro, RJ: Diário Oficial do Estado, 18 out. 2017. Disponível em: http://alerjln1.alerj.rj.gov.br/contlei.nsf/c8aa0900025feef6032564ec0060dfff/0b1 10d0140b3d479832581c3005 b82ad?OpenDocument\&ExpandSection=-1\%2C-5\&Highlight=0,7753\#_Section1. Acesso em: 19 maio 2020.

ROSE-ACKERMAN, Susan. La Corrupción y los Gobiernos: Causas, consecuencias y reforma. $1^{\text {a }}$ ed. Madrid, España: Siglo XXI de España Editores, 2001. ISBN 84-323-1063-8.

SILVEIRA, Renato de Mello Jorge; SAAD-DINIZ, Eduardo. Compliance, Direito Penal e Lei Anticorrupção. $1^{\text {a }}$ ed. São Paulo: Saraiva, 2015.

SPORKIN, Stanley. The Worldwide Banning of Schmiergeld: A Look at the Foreign Corrupt Practices Act on its Twentieth Birthday. Northwestern Journal of International Law \& Business, Chicago, IL, v. 18, n. 2, p. 271-272, 1997-1998.

TRIBUNAL DE CONTAS DA UNIÃO (TCU). REFERENCIAL BÁSICO DE GOVERNANÇA. Brasília, DF: 2ª v. 2014. Disponível em: https://portal.tcu.gov.br/data/files/84/34/1A/4D/43B0F410E827A0F42A2818A8/2663788.PDF. Acesso em: 2 set. 2020.

VENTURINI, Otavio; CARVALHO, André Castro; MORELAND, Allen. Aspectos Gerais do U.S Foreign Corrupt Practices Act (FCPA). In: CARVALHO, André Castro; BERTOCCELLI, Rodrigo de Pinho; ALVIM, Tiago Cripa; VENTURINI, Otavio. Manual de Compliance. Rio de Janeiro: Forense, 2019. cap. 16, p. 319-348. ISBN 9788530983154.

VILA VELHA. LEI n 6.050, de 27 de agosto de 2018. DISPÕE SOBRE A OBRIGATORIEDADE DA IMPLANTAÇÃO DO PROGRAMA DE INTEGRIDADE (COMPLIANCE) NAS EMPRESAS QUE CONTRATAREM COM A ADMINISTRAÇÃO PÚBLICA DO MUNICÍPIO DE VILA VELHA, EM TODAS ESFERAS DE PODER, E DÁ OUTRAS PROVIDÊNCIAS. [S. I.]: Diário Oficial do Município, 28 ago. 2018. Disponível em: https://www.vilavelha.es.gov.br/legislacao/Arquivo/ Documents/legislacao/html/L60502018.html. Acesso em: 18 maio 2020.

Recebido/Received: 03.07.2020.

Aprovado/Approved: 26.09.2020. 